\title{
FAMILY BURDEN AND STRESS AMONG CAREGIVER OF ORAL CANCER PATIENTS AT KRISHNA HOSPITAL KARAD
}

\author{
PRABHUSWAMI HIREMATH*, VAISHALI R MOHITE, PRAKASH NAREGAL, MAHESH CHENDAKE, AFSANA MULANI, \\ UJWALA R MORE
}

Department of Nursing Sciences, Krishna Institute of Nursing Sciences, Karad, Maharashtra, India. Email: prabhuh252003@gmail.com

\author{
Received: 03 November 2016, Revised and Accepted: 17 December 2016
}

\begin{abstract}
Objectives: Cancer is a major life-threatening disease and has its impact on both patients and their family members. Caregivers also play the very important role in the care of the patients with cancer. (1) Asses the burden among caregivers of patients with oral cancer using burden inventory. (2) Assess the perceived stress among caregivers of patients with oral cancer using Perceived Stress Scale (PSS). (3) Identify the correlation between burden and perceived stress with selected sociodemographic variable. There is mounting evidence that during advanced stages of illness, changes in family roles, and the burden placed on family caregivers may negatively affect quality of life for cancer patients, as well as their caregivers. Attending to the needs of the families of patients not only will benefit family members but also may help patients with their own emotional responses and management of their disease. The study objectives were to asses the burden and the perceived stress among caregivers of patients with oral cancer patients.
\end{abstract}

Methods: Quantitative nonexperimental approach with descriptive survey design was selected for study. 40 caregivers of patients with oral cancer were selected through convenience sampling technique. The study included the caregivers of 21-50 years age group who is providing care patients with oral cancers, who are responding and interested to participate, and available at the time of the study. Caregiver's burden was assessed using caregiver burden scale. A stress of the caregiver was assessed by the PSS.

Results: Demographic variable shows that maximum sample belongs 40-50 (40\%) years of age group, male gender (65\%), married (90\%), nuclear family $(65 \%)$, house wife by occupation $(60 \%)$, spouse to the patients (45\%), below graduated education ( $72 \%), 6$ months to 1 year in providing care (47\%), having health benefit from government (52\%), and accompanying patient regularly to the hospital (72\%). In this study, 3 (7.5\%) caregiver were said that no burden, 13 (32.5\%) samples shown mild burden, 15 (37.5\%) relative indicated moderate burden, and 9 (22.5\%) samples shown severe burden; 4 (10\%) samples shown low stress, 22 (55\%) caregiver presented moderate stress, and 14 (35\%) samples had high stress.

Conclusion: Caregivers are often patients' primary source of support, many experience significant burden, particularly with respect to their physical and psychological well-being, economic circumstances, and social and personal relationships.

Keywords: Family, Burden, Stress, Caregiver, Oral cancer.

(C) 2017 The Authors. Published by Innovare Academic Sciences Pvt Ltd. This is an open access article under the CC BY license (http://creativecommons. org/licenses/by/4. 0/) DOI: http://dx.doi.org/10.22159/ajpcr.2017.v10i3.16010

\section{INTRODUCTION}

Cancer is a major life-threatening disease and has its impact on both patients and their family members. Caregivers also play the very important role in the care of the patients with cancer. Cancers are the most common cause of death in adults [1]. A worldwide variety of studies has found that when individuals have low levels of social support, they experience worse outcomes, including higher mortality rates (Institute of Medicine, 2001). The caregivers are the close relatives/family member/individuals assisting for patients who have oral cancer and are unable to independently care for themselves or need assistance to manage their care related to cancer or cancer treatment and their daily living activities. The majority of caregivers were first degree relatives and reported that their caregiving responsibilities are experienced as a burden. Caregiver burden is the distress that caregivers feel as a result of providing care. It is specific to oral cancer patient care and differs from anxiety, depression, and other emotional and more general responses. This burden may be due to increased caregiver demands that accompany the progressive deterioration of the patients.

Oral cancer is any malignant neoplasm which is found on the lip, floor of the mouth, cheek lining, gingiva, palate or in the tongue. Tobacco chewing is the major etiological factor in its development. Other factors include alcohol, genetic factors, and diet lacking in micronutrients and vitamins [2]. Oral cancer is among the top three types of cancers in India. Right from the diagnosis of the disease till the end care the patients are completely dependent on family members. Not only family members suffer from financial burden but also it have its impact on their psychosocial aspect of life. Relatives living in low socioeconomic status are the one who suffers a lot due to the patient's care [3]. On diagnosis, families often find themselves grappling with intense emotions and existential concerns at the same time as they are providing support to patients, taking on personal caregiving roles and responsibilities and attempting to remain afloat with other competing life events. Patients and their caregivers may be worrying about using coping strategies and adjust to potential disruptions in routines and activities. Despite efforts to manage care giving demands these may inadvertently exceed caregivers' capabilities and result in them feeling stressed [4]. Caregiving role may extend for several years and roles/ tasks can involve a considerable number of hours per week, which for some is comparable to a full-time job [5]. According to patients' diagnosis and illness severity, caregiving may require mastery of tasks typically performed by health-care professionals, including symptom management, nutrition support, implementation of a treatment regimen, management of acute illness episodes, and providing help with activities of daily living (e.g., getting in and out of bed, feeding, getting dressed, and bathing) [5]. 
There is a lot of evidence that during advanced stages of illness, caring for chronically ill may adversely affect on family caregivers negatively on quality of life (QoL). It was found that patients' dependencies in tasks of daily living, symptom severity, and immobility had a direct effect on the burden and depression experienced by family members providing care. It also showed that older caregivers seem to have difficulty with tasks and physical demands of spouse illness, whereas the difficulties of younger couples are in the affective domain. These younger individuals may feel frustrated and sad. As per gender is considered, females experience more distress than males. Family members of patients with cancer experience higher-than-normal stress due to multiple reasons, including fear of losing their loved one, concern about the suffering of their family member, and the additional demands of providing emotional and logistical support and hands-on care during times of acute illness [6,7]. High stress levels in caregivers can interfere with their ability to provide the emotional or logistical support patients need. Problematic family relationships that predate the onset of cancer also can lead to inadequate support from the family [7]. Both of these situations can exacerbate the patient's stress, which in turn can contribute to the patient's poorer adjustment to the illness. Thus, attending to the needs of the families of patients not only will benefit family members but also may help patients with their own emotional responses and management of their disease [8]. Families who sacrifice so much for the care of their loved ones deserve access to effective interventions and psychological care [9]. The aim of this study is to understand the family burden and stress of relatives of oral cancer patient and the results may help to prepare family members to cope with patients complication and treatment.

\section{The objectives of the study were as follows}

1. Asses the burden among caregivers of patients with oral cancer using burden inventory

2. Assess the perceived stress among caregivers of patients with oral cancer using Perceived Stress Scale (PSS)

3. Identify the correlation between burden and perceived stress with selected sociodemographic variable.

\section{METHODS}

Quantitative nonexperimental approach with descriptive survey design was selected for study. Approval from the medical director and head of the oncology department was obtained. 40 caregivers (family caregivers, including parents, spouses, children, and next of kin, who were the main caregivers) of patients with oral cancer were selected through convenience sampling technique. Before the study, participants were informed verbally about the aim of the study; any doubts or questions raised by the participant or family member were clarified. It was mentioned that they could withdraw from the study at any time; then informed consent was obtained. To protect the privacy, confidentiality, and the identity of the participants, interviews were conducted only with the participation of the interviewer and the interviewee. The study included the caregivers of 21-50 years age group who is providing care patients with oral cancers, who are responding and interested to participate, and available at the time of the study. Exclusion criteria were caregivers of the patients who are terminally ill and at the end-of-life stage, receiving only palliative and supportive treatments, who are taking care of the patients for temporary period or not regular caregivers or any professional worker and caregivers of patients diagnosed with other types of cancer.

\section{Data collection tools and technique}

Caregiver's burden was assessed using caregiver burden scale [10], is a sum of the items for which the patient needed assistance and the caregiver provided assistance and the caregiver reported that providing this assistance was stressful. The possible range was 0-15.

A stress of the caregiver was assessed by the PSS [11], self-report measure of stress most widely used psychological instrument for measuring the perception of stress. Items were designed to tap how unpredictable, uncontrollable, and overloaded respondents find their lives. The scale also includes a number of direct queries about current levels of experienced stress. The PSS has a range of scores between 0 and 40. A higher score indicates more stress.

\section{RESULTS}

Table 1 show demographic variable shows that maximum sample belongs 40-50 (40\%) years of age group, male gender (65\%), married (90\%), nuclear family (65\%), house wife by occupation $(60 \%)$, spouse to the patients (45\%), below graduated education (72\%), 6 months to 1 year in providing care (47\%), having health benefit from government (52\%), and accompanying patient regularly to the hospital (72\%).

\section{Distribution of sample according to caregiving burden}

Table 2 show burden scale score range from 0 to 15, 0 being no burden and 15 indicates severe burden. According to the range 1-5 indicate

Table 1: Description of sample characteristics $(n=40)$

\begin{tabular}{|c|c|c|}
\hline S. No. & Demographic variables & Frequency $(\%)$ \\
\hline \multirow[t]{5}{*}{1.} & Family caregiver age & \\
\hline & $<30$ & $5(12.5)$ \\
\hline & $30-40$ & $13(32.5)$ \\
\hline & $40-50$ & $16(40)$ \\
\hline & $<50$ & $6(15)$ \\
\hline \multirow[t]{3}{*}{2.} & Gender of caregiver & \\
\hline & Male & $14(35)$ \\
\hline & Female & $26(65)$ \\
\hline \multirow[t]{4}{*}{3.} & Marital status of caregiver & \\
\hline & Married & $36(90)$ \\
\hline & Unmarried & $4(10)$ \\
\hline & Divorced & $0(0)$ \\
\hline \multirow[t]{3}{*}{4.} & Types of family of caregiver & \\
\hline & Nuclear & $26(65)$ \\
\hline & Joint family & $14(35)$ \\
\hline \multirow[t]{5}{*}{5.} & Occupation of caregiver & \\
\hline & Full-time work & $12(30)$ \\
\hline & Unemployed & $0(0)$ \\
\hline & Retired & $4(10)$ \\
\hline & House wife & $24(60)$ \\
\hline \multirow[t]{6}{*}{6.} & Relationship to the patient of caregiver & \\
\hline & Son & $5(12.5)$ \\
\hline & Daughter & $8(20)$ \\
\hline & Spouse & $18(45)$ \\
\hline & Sister/Brother & $6(15)$ \\
\hline & Other relatives & $3(7.5)$ \\
\hline \multirow[t]{5}{*}{7.} & Education of caregiver & \\
\hline & Uneducated & $0(0)$ \\
\hline & Below graduation & $29(72.5)$ \\
\hline & Graduation & $8(20)$ \\
\hline & Postgraduation & $3(7.5)$ \\
\hline \multirow[t]{5}{*}{8.} & Length of time involved in caregiving & \\
\hline & $0-6$ months & $9(22.5)$ \\
\hline & 6 months - 1 years & $19(47.5)$ \\
\hline & $1-3$ years & $8(20)$ \\
\hline & More than 3 years & $4(10)$ \\
\hline \multirow[t]{3}{*}{9.} & $\begin{array}{l}\text { Health insurance/government health } \\
\text { benefits }\end{array}$ & \\
\hline & Yes & $21(52.5)$ \\
\hline & No & $19(47.5)$ \\
\hline \multirow[t]{3}{*}{10.} & Accompanying patient to hospital & \\
\hline & Yes & $29(72)$ \\
\hline & No & $11(28)$ \\
\hline
\end{tabular}

Table 2: Level of burden among caregiver

\begin{tabular}{lll}
\hline Grading & Range & Frequency (\%) \\
\hline No burden & 0 & $3(7.5)$ \\
Mild burden & $1-5$ & $13(32.5)$ \\
Moderate burden & $6-10$ & $15(37.5)$ \\
Severe burden & $11-15$ & $9(22.5)$ \\
\hline
\end{tabular}


Table 3: Level of burden among caregiver according to demographic variables

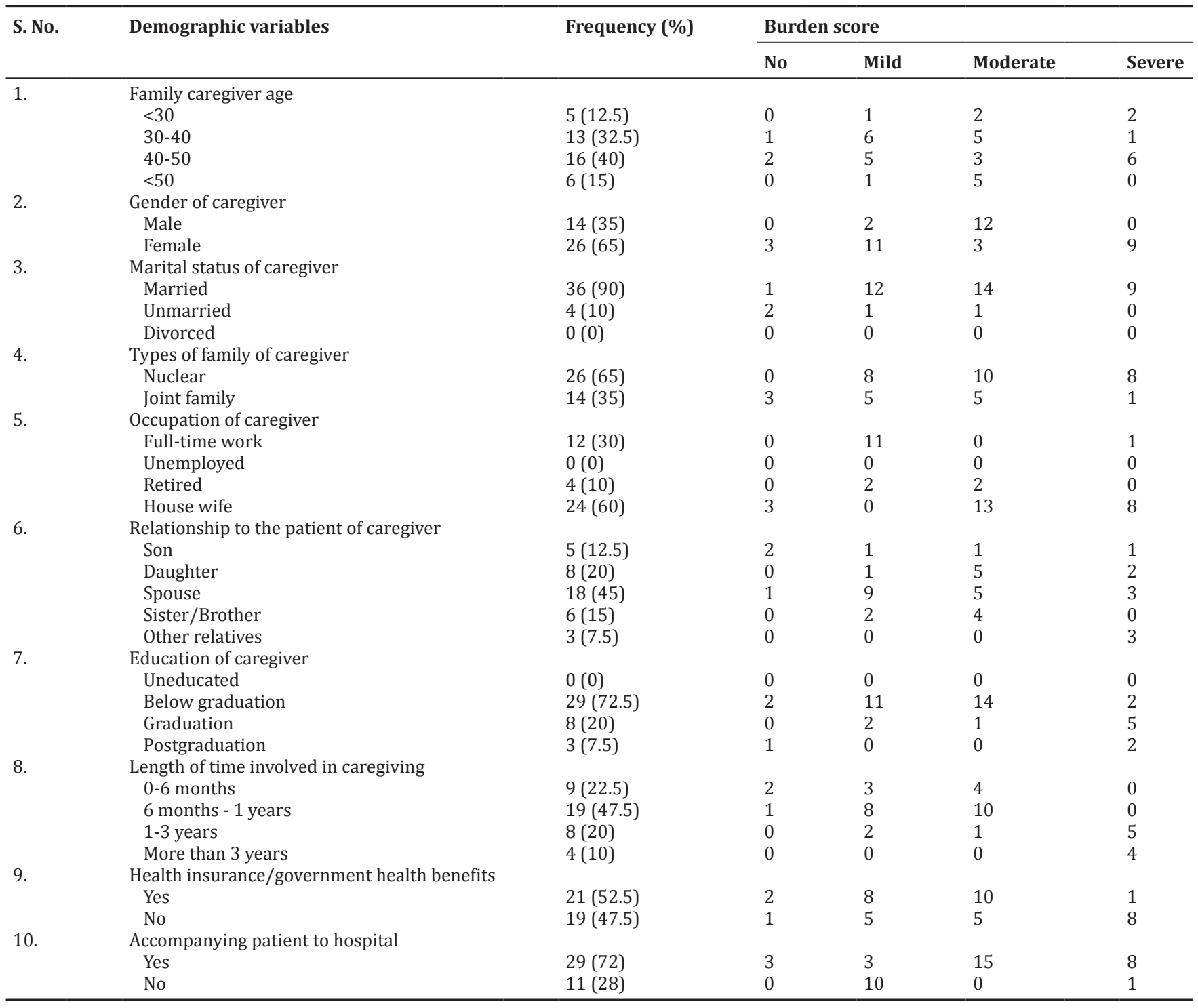

mild burden, $6-10$ shows moderate, and $11-15$ is considered as a severe burden. Table 3 shows, 3 (7.5\%) caregivers were said that no burden, $13(32.5 \%)$ samples show mild burden, 15 (37.5\%) relative indicated moderate burden, and 9 (22.5\%) samples shown severe burden.

\section{PSS}

Table 4 show stress score summarizes the low level of stress indicates 1-13 range, moderate $14-26$, and high stress indicates when score 27-40. Table 5 shows, 4 (10\%) samples shown low stress, 22 (55\%) caregiver presented moderate stress, and 14 (35\%) samples had high stress.

\section{Perceived stress score according to demographic variables}

Association Table 6 shows age being a highly significant, marital status of caregiver, types of family of caregiver, relationship to the patient of caregiver, government health policies and accompanying patient to hospital were significant and education of caregiver, length of time involved in caregiving were not having any association.

Table 7 show association with stress level with demographic characteristics shows age is having high significance, occupation of caregiver, relationship to the patient of caregiver, education of caregiver, health insurance/ government health benefits, accompanying patient to hospital were significant, and rest of the variables were not having any significance.
Table 4: PSS

\begin{tabular}{lll}
\hline Grading & Range & Frequency (\%) \\
\hline Low stress & $1-13$ & $04(10)$ \\
Moderate stress & $14-26$ & $22(55)$ \\
High stress & $27-40$ & $14(35)$
\end{tabular}

PSS: Perceived stress score

\section{DISCUSSION}

Many studies reported that high burden or moderate to severe burden are common in caregiver of cancer. Study by Grunfeld et al. [13] shows higher level of perceived burden (26.2 vs. 19.4, p = 0.02) among caregiver at the start of the terminal period than at the start of the palliative period. Of employed caregivers, $69 \%$ reported some form of adverse impact on work. In the terminal period, $77 \%$ reported missing work because of caregiving responsibilities. Prescription drugs were the most important component of financial burden.

Rachela Pellegrino et al. [14] also showed caregivers of cancer patients experience high levels of stress that may significantly impact their QoL with 104 caregivers at patient pairs University of Rome, Rome. Most of the caregivers (52\%) spent more than $8 \mathrm{hrs}$ daily caring for the patient, 
Table 5: PSS according to demographic variables

\begin{tabular}{|c|c|c|c|c|c|}
\hline \multirow[t]{2}{*}{ S. No. } & \multirow[t]{2}{*}{ Demographic variables } & \multirow[t]{2}{*}{ Frequency (\%) } & \multicolumn{3}{|c|}{ Stress score } \\
\hline & & & Mild & Moderate & Severe \\
\hline \multirow[t]{4}{*}{1.} & Family caregiver age & & & & \\
\hline & $30-40$ & $13(32.5)$ & 1 & 6 & 6 \\
\hline & $40-50$ & $16(40)$ & 3 & 9 & 4 \\
\hline & $<50$ & $6(15)$ & 0 & 2 & 4 \\
\hline \multirow[t]{3}{*}{2.} & Gender of caregiver & & & & \\
\hline & Male & $14(35)$ & 1 & 4 & 9 \\
\hline & Female & $26(65)$ & 3 & 18 & 5 \\
\hline \multirow[t]{4}{*}{3.} & Marital status of caregiver & & & & \\
\hline & Married & $36(90)$ & 12 & 11 & 13 \\
\hline & Unmarried & $4(10)$ & 2 & 1 & 1 \\
\hline & Divorced & $0(0)$ & 0 & 0 & 0 \\
\hline \multirow[t]{3}{*}{4.} & Types of family of caregiver & & & & \\
\hline & Nuclear & $26(65)$ & 1 & 15 & 10 \\
\hline & Joint family & $14(35)$ & 3 & 7 & 4 \\
\hline \multirow{4}{*}{5.} & Full-time work & $12(30)$ & 2 & 0 & 10 \\
\hline & Unemployed & $0(0)$ & 0 & 0 & 0 \\
\hline & Retired & $4(10)$ & 0 & 2 & 2 \\
\hline & House wife & $24(60)$ & 2 & 10 & 12 \\
\hline \multirow[t]{6}{*}{6.} & Relationship to the patient of caregiver & & & & \\
\hline & Son & $5(12.5)$ & 0 & 3 & 2 \\
\hline & Daughter & $8(20)$ & 0 & 5 & 3 \\
\hline & Spouse & $18(45)$ & 1 & 10 & 7 \\
\hline & Sister/Brother & $6(15)$ & 1 & 3 & 2 \\
\hline & Other relatives & $3(7.5)$ & 2 & 1 & 0 \\
\hline \multirow[t]{5}{*}{7.} & Education of caregiver & & & & \\
\hline & Uneducated & $0(0)$ & 0 & 0 & 0 \\
\hline & Below graduation & $29(72.5)$ & 4 & 13 & 12 \\
\hline & Graduation & $8(20)$ & 0 & 8 & 0 \\
\hline & Postgraduation & $3(7.5)$ & 0 & 1 & 2 \\
\hline \multirow[t]{3}{*}{8.} & Length of time involved in caregiving & & & & \\
\hline & $0-6$ months & $9(22.5)$ & 1 & 5 & 6 \\
\hline & More than 3 years & $4(10)$ & 0 & 2 & 2 \\
\hline \multirow[t]{3}{*}{9.} & $\begin{array}{l}\text { Health insurance/government health } \\
\text { benefits }\end{array}$ & & & & \\
\hline & Yes & $21(52.5)$ & 0 & 3 & 4 \\
\hline & No & $19(47.5)$ & 4 & 19 & 10 \\
\hline \multirow[t]{3}{*}{10.} & Accompanying patient to hospital & & & & \\
\hline & Yes & $29(72)$ & 4 & 10 & 15 \\
\hline & No & $11(28)$ & 0 & 9 & 2 \\
\hline
\end{tabular}

PSS: Perceived Stress Score

Table 6: Association of family burden according with sociodemographic variable

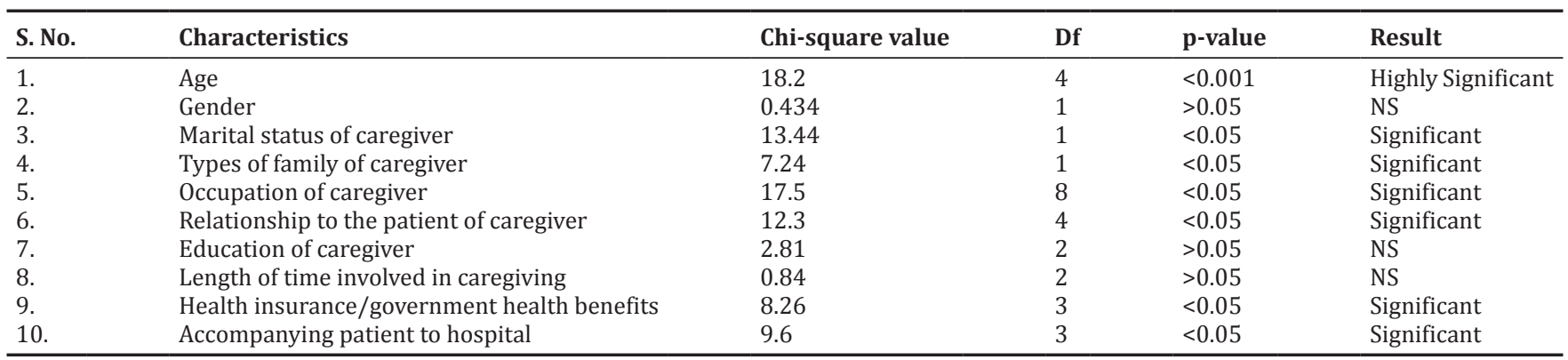

they also frequently reported the occurrence of new psychosomatic disorders, with the most reported symptoms being sleep disruption $(24 \%)$, headaches $(20 \%)$, and asthenia (16\%). High levels of anxiety and depression were demonstrated in nearly a quarter of the study subjects. A substantial increase in monthly family expenses and restriction of recreation activities were reported. The overall gravity of the medical situation was perceived as severe by $86 \%$ of the caregiver.
Financial burden is one of the most sensible issues for caregiver. $72 \%$ of the family caregiver comes to hospital in every visit which disrupts in their daily routine and have to spend more earning on transportation and meals besides routine treatment expenses. These results are similar to Kaiser family foundation report in the USA who surveyed 930 adult caregiver which found that nearly half of the samples were had burden $68 \%$ of caregiver were unable to do their job as before, $25 \%$ of samples 
Table 7: Association with stress level with demographic characteristics

\begin{tabular}{|c|c|c|c|c|c|}
\hline S. No. & Characteristics & Chi-square value & Df & p-value & Result \\
\hline 1. & Age & 16.2 & 4 & $<0.001$ & Highly Significant \\
\hline 2. & Gender & 0.834 & 1 & $>0.05$ & NS \\
\hline 3. & Marital status of caregiver & 17.44 & 1 & $>0.05$ & NS \\
\hline 4. & Types of family of caregiver & 9.24 & 1 & $>0.05$ & NS \\
\hline 5. & Occupation of caregiver & 11.5 & 8 & $<0.05$ & Significant \\
\hline 6. & Relationship to the patient of caregiver & 14.3 & 4 & $<0.05$ & Significant \\
\hline 7. & Education of caregiver & 3.81 & 3 & $<0.05$ & Significant \\
\hline 9. & Health insurance/government Health benefits & 9.26 & 3 & $<0.05$ & Significant \\
\hline 10. & Accompanying patient to hospital & 10.6 & 3 & $<0.05$ & Significant \\
\hline
\end{tabular}

used most of their saving for the treatment [15]. Many caregivers report deep levels of satisfaction from their caring role. However, many more experience significant burden, particularly with respect to their physical and psychological well-being, economic circumstances, and social and personal relationships [16].

A cross-sectional, hospital based study conducted in in Delhi with 200 family caregivers of cancer patients, by Longacre et al. [17] shows $113(56.5 \%)$ caregivers had no or minimal burden while 75 (37.5\%) caregivers reported mild to moderate burden. Only $2(1 \%)$ caregivers reported severe burden. Mean burden scores as assessed by Zarit Burden Interview was $20 \pm 11$ (median=18). In view of the substantial burden on family caregivers coupled with lack of adequate number of cancer hospitals, there is a public health imperative to recognize this important group. All levels of health-staff in cancer hospitals in developing countries should be sensitized to the various burdens faced by family caregivers. Moderate to high stress was perceived among caregivers in our study. These results are similar to Goldzweig et al. [18] Northouse et al. [19].

Family Caregivers' burden and patients' functional status are closely associated [12]. There are studies which show Caregivers' burden increase as patients' functional status declines [13]. Regarding social context S Lukhmana et al. [17] stressed that in India societal norms are such that taking care of the diseased spouse is considered the duty of the otherwise healthy partner. Cultural norms dictate that a good relationship between parents and their adult children is fostered throughout a lifetime. Parents sacrifice for their children and adult children are obliged to take care of their elders when either of them is diseased, and therefore, they continue to look after the ill member without any apparent complaints or feeling burdened. Hence, the level of burden decreases when compared to foreign research.

\section{Summary}

Caregivers are often patients' primary source of support, many experience significant burden, particularly with respect to their physical and psychological well-being, economic circumstances, and social and personal relationships. There is currently little support available specifically to assist caregivers in undertaking this important task. Health-care professionals are well placed to identify caregivers who may be at risk of significant burden and to support them through direct care or by referral to appropriate services to help meet their needs [16].

\section{Recommendations}

A recent meta-analysis by Northouse et al. [20] found that three types of interventions are typically offered to caregivers: Psychoeducational, skills training (coping, communication, and problem-solving skills), and therapeutic counseling. Although these interventions were found to have small to medium effects, they significantly reduced caregiver burden, enhanced coping behavior, increased self-efficacy (i.e., perceived confidence, preparation, and/or mastery to provide care), and improved aspects of QoL.

Northouse et al. suggested that development of standardized guidelines that address caregiver assessment, education, and resources; will help in improvement of care to the clients and also identification of "caregiver champions" in practice settings; provision of referrals to established support organizations for caregivers (e.g., cancer support community, cancer care); collaboration among caregiving, professional, and cancerrelated organizations to advocate policy and practice changes for family caregivers would provide better enhancement in nonprofessional care by caregivers [21].

\section{REFERENCES}

1. Dikshit R, Gupta PC, Ramasundarahettige C, Gajalakshmi V, Aleksandrowicz L, Badwe $\mathrm{R}$, et al. Cancer mortality in India: A nationally representative survey. Lancet 2012;379(9828):1807-16.

2. Manasaveena V, Akula KK, Sangram V. A comparative evaluation of enzymatic antioxidant levels in pre and post therapy patients with oral cancer. Int J Pharm Pharm Sci 2014;6(11):52-6.

3. Girgis A, Lambert S. Caregivers of Cancer Survivors: The State of the Field Survivorship. Vol. 33. NSW. Cancer Council NSW; University of Newcastle and Hunter Medical Research Institute; 2009.

4. Kim Y, Schulz R. Family caregivers' strains: Comparative analysis of cancer caregiving with dementia, diabetes, and frail elderly caregiving. J Aging Health 2008;20(5):483-503.

5. Hodges LJ, Humphris GM, Macfarlane G. A meta-analytic investigation of the relationship between the psychological distress of cancer patients and their carers. Soc Sci Med 2005;60(1):1-12.

6. Kotkamp-Mothes N, Slawinsky D, Hindermann S, Strauss B. Coping and psychological well being in families of elderly cancer patients. Crit Rev Oncol Hematol 2005;55(3):213-29.

7. Cancer Care for the Whole Patient: Meeting Psychosocial Health Needs. Available from: http://www.ncbi.nlm.nih.gov/books/ NBK4008.

8. McMillan SC, Small BJ, Weitzner M, Schonwetter R, Tittle M, Moody L, et al. Impact of coping skills intervention with family caregivers of hospice patients with cancer: A randomized clinical trial. Cancer 2006;106(1):214-22.

9. Macera CA, Eaker ED, Jannarone RJ, Davis DR, Stoskopf CH. A measure of perceived burden among caregivers. Eval Health Prof 1993;16(2):205-11.

10. Available from: http://www.providencecare.ca/clinical-tools/ Kingston-Scales/Kingston\%20Scales/2013-Welcome-KS.pdf.

11. Folkman S, Lazarus RS, Dunkel-Schetter C, DeLongis A, Gruen RJ. Dynamics of a stressful encounter: Cognitive appraisal, coping, and encounter outcomes. J Pers Soc Psychol 1986;50(5):992-1003.

12. Grunfeld E, Coyle D, Whelan T, Clinch J, Reyno L, Earle CC, et al. Family caregiver burden: Results of a longitudinal study of breast cancer patients and their principal caregivers. Can Med Assoc J 2004; 170(12):1795-801

13. Rachela P, Formica V, Arena PI, Mariotti S, Grenga I, Monte DG, et al. Caregiver distress in the early phases of cancer. Anticancer Res 2010;30(11):4657-63.

14. Henry J. The Kaiser Family Foundation: National Survey of Households Affected by Cancer; 2006. Available from: http://www.kff.org

15. Girgis A, Lambert S, Johnson C, Waller A, Currow D. Physical, psychosocial, relationship, and economic burden of caring for people with cancer: A review. J Oncol Pract 2013;9(4):197-202.

16. Lukhmana S, Bhasin SK, Chhabra P, Bhatia MS. Family caregivers' burden: A hospital based study in 2010 among cancer patients from Delhi. Indian J Cancer 2015;52(1):146-51.

17. Longacre ML, Ross EA, Fang CY. Caregiving choice and emotional stress among cancer caregivers. West J Nurs Res 2014;36(6):806-24 
18. Goldzweig G, Merims S, Ganon R, Peretz T, Altman A, Baider L. Informal caregiving to older cancer patients: Preliminary research outcomes and implications. Ann Oncol 2013;24(10):2635-40.

19. Northouse LL, Katapodi MC, Song L, Zhang L, Mood DW. Interventions with family caregivers of cancer patients: Meta-analysis of randomized trials. CA Cancer J Clin 2010;60(5):317-39.
20. Northouse L, Williams AL, Given B, McCorkle R. Psychosocial care for family caregivers of patients with cancer. J Clin Oncol 2012;30(11):1227-34.

21. Northouse L, Williams A, Given B, McCorkle R. Psychosocial care for family caregivers of patients with cancer. J Clin Oncol 2012;30(11):1227-34. 